\title{
Effect of Diet versus Diet and Exercise on Weight Loss and Body Composition in Class II and III Obesity: A Systematic Review
}

\author{
Clint T Miller ${ }^{1}$, Steve F Fraser ${ }^{1}$, Nora E Straznicky², John B Dixon ${ }^{3}$, Steve E Selig ${ }^{1}$ and Itamar Levinger ${ }^{4 *}$
}

${ }^{1}$ Centre for Exercise and Sports Science, School of Exercise and Nutrition Sciences, Deakin University, Australia

${ }^{2}$ Human Neurotransmitters Laboratory, Baker IDI Heart and Diabetes Institute, Australia

${ }^{3}$ Vascular Hypertension and Obesity Laboratory, Baker IDI Heart and Diabetes Institute, Australia

${ }^{4}$ Institute of Sport, Exercise and Active Living (ISEAL), College of Sport and Exercise Science, Victoria University, Australia

\begin{abstract}
Class II and III obesity (BMI $>35 \mathrm{~kg} \cdot \mathrm{m}^{2}$ ) have increased dramatically in recent years. Current clinical guidelines suggest diet and exercise as first line treatment for adults throughout the spectrum of overweight and obesity. However, to date there is no systematic review that examines the effects of diet and exercise on this high risk population. This systematic review will examine the combined effects of diet versus diet and exercise on body composition in severe obesity. Medline and Cinahl were searched for randomised controlled trials comparing diet and exercise to diet alone. Studies published until July 2013 were included if they used reliable methods for analysing body composition in adults with $\mathrm{BMI} \geq 35 \mathrm{~kg} \cdot \mathrm{m}^{2}$. Five of 459 studies met the inclusion criteria. Two studies, both in older adults, reported that exercise reduced lean mass loss during weight loss. Two studies showed that exercise facilitated (greater) fat mass loss. The remaining study reported no differences in body composition when exercise is added to energy restriction. Exercise training during energy restriction for individuals with $\mathrm{BMI} \geq 35 \mathrm{~kg} \cdot \mathrm{m}^{2}$ may influence body composition outcomes but the evidence is limited. Further studies should focus on the efficacy of different exercise protocols during energy restriction for this population in order to better inform decision making for the treatment of severe obesity in respect to favourable body composition outcomes.
\end{abstract}

Keywords: Diet; Exercise; Weight loss; Obesity

\section{Introduction}

Around one quarter of Australian and one third of US adults are classified as obese [1]. Further, there is evidence of an acceleration in prevalence of those approaching Class III obesity (body mass index, BMI $\geq 40 \mathrm{~kg} \cdot \mathrm{m}^{2}$ ), compared to overweight and Class I obese individuals (BMI 25-34.9 $\left.\mathrm{kg} \cdot \mathrm{m}^{2}\right)$ [2]. Individuals in Classes II and III are at a higher risk of developing metabolic and cardiovascular disease compared to those with overweight and class I obesity $[3,4]$. Also those individuals place twice the burden on the health care system in developed countries than normal weight individuals [5]. Surprisingly, little is known in regard to combined diet and exercise in severely obese individuals despite lifestyle modification being considered a key strategy for the management of health in overweight, obese and severely obese individuals [6,7]. In addition to weight loss, lifestyle interventions can lead to improved quality of life and reduced morbidity and mortality in overweight and obese individuals [8].

The accumulation of visceral adipose tissue is an established risk factor for insulin resistance, diabetes and metabolic syndrome [9]. Reduction of visceral adipose tissue significantly improves glucose tolerance and insulin sensitivity, whilst the loss of subcutaneous adipose tissue alone is ineffective for improving metabolic health outcomes [10]. Exercise may provide some preferential visceral adipose tissue loss during the early phase of weight loss programs, however total weight loss over the long term may have the greatest influence on visceral fat reduction $[11,12]$. Changes in body mass is commonly used to determine the success of weight loss programs; however this fails to differentiate between fat mass and lean mass which are both typically lost during energy restriction [13]. It is important that for obesity treatments to be effective they result in a loss of fat mass and limit the loss of lean mass. The prevention of fat free mass loss is integral to the preservation of sufficient resting metabolic activity, core body temperature, skeletal integrity, functional capacity and the prevention of sarcopenic obesity later in life [14-16]. Energy restriction results in more rapid weight loss compared to exercise alone in mildly obese individuals but fails to adequately mitigate the loss of fat free mass $[13,17]$. The addition of regular exercise training during an energy controlled diet may attenuate the loss of fat free mass [13], improve muscle quality, enhance functional capacity, and reduce cardiometabolic risk factors [18-20].

The effects of exercise in addition to energy restriction on fat free mass in middle-aged and older overweight or obese adults has been investigated in a recent systematic review [17]. This review showed that exercise in addition to energy restriction in older adults may attenuate the loss of fat free mass compared to energy restriction alone but plays little role in the facilitation of greater fat mass loss. This is similar to an earlier review of overweight and mildly obese adults [21]. Both reviews are limited by the inclusion of studies that employ the use of body composition techniques that are less sensitive and reliable in obese adults during phases of weight change by estimating fat free mass according to general assumptions of total body water and bone mineral density $[14,22,23]$. These reviews also include studies with a wide mean BMI range incorporating overweight, and mildly to severely obese adults. No reviews to our knowledge have been published to assess the

*Corresponding author: Itamar Levinger , Institute of Sport, Exercise and Active Living (ISEAL), College of Sport and Exercise Science, Victoria University , PO Box 14428, Melbourne, VIC 8001, Australia, Tel: (61-3) 9919 5343; Fax: (61-3) 9919 5532; E-mail: itamar.levinger@vu.edu.au

Received July 09, 2013; Accepted August 13, 2013; Published August 17, 2013

Citation: Miller CT, Fraser SF, Straznicky NE, Dixon JB, Selig SE, et al. (2013) Effect of Diet versus Diet and Exercise on Weight Loss and Body Composition in Class II and III Obesity: A Systematic Review. J Diabetes Metab 4: 281. doi:10.4172/2155-6156.1000281

Copyright: @ 2013 Miller CT, et al. This is an open-access article distributed under the terms of the Creative Commons Attribution License, which permits unrestricted use, distribution, and reproduction in any medium, provided the original author and source are credited. 
body composition outcomes for adults with severe obesity following an energy restricted diet alone or combined with exercise training.

Clinical practice guidelines globally recommend lifestyle modification for first line treatment for obesity without strong evidence for its effectiveness in class II and III obesity [24-27]. The purpose of this paper was to examine the evidence for exercise training during energy restriction in terms of body composition outcomes for individuals with clinically severe obesity $\left(\mathrm{BMI} \geq 35 \mathrm{~kg} \cdot \mathrm{m}^{2}\right)$.

\section{Methods}

Search strategy: Medline and Cinahl electronic databases were searched (Figure 1) for randomised controlled trials (RCTs) published to July 2013 using the following search strategy: keyword and categorical searches were performed (i) body composition, visceral, whole body, magnetic resonance imaging, MRI, plethysmography, underwater weighing, UWW, dual x-ray absorptiometry, dual energy $\mathrm{x}$-ray absorptiometry, DEXA, DXA, lean mass, fat free mass, fat mass, FM, FFM; (ii) obesity, obese, (iii) physical activity, exercise. In addition, reference lists of publications meeting the inclusion criteria were manually searched to identify any relevant studies not found through electronic searches. The first author, CM, independently assessed the suitability of each study for inclusion and a second author, IL, confirmed it. Disagreements were resolved by discussion between the two researchers.

Inclusion and exclusion criteria: Only RCTs that met the following criteria were included in this review: (i) published in English, (ii) participants were adults aged above 18 years, (iii) the same dietary intervention was used in the diet only and combined exercise and diet arms of the study, (iv) mean BMI of participants $\geq 35 \mathrm{~kg} \cdot \mathrm{m}^{-2}$, (v) accepted methods of assessing body composition, including any of (a)

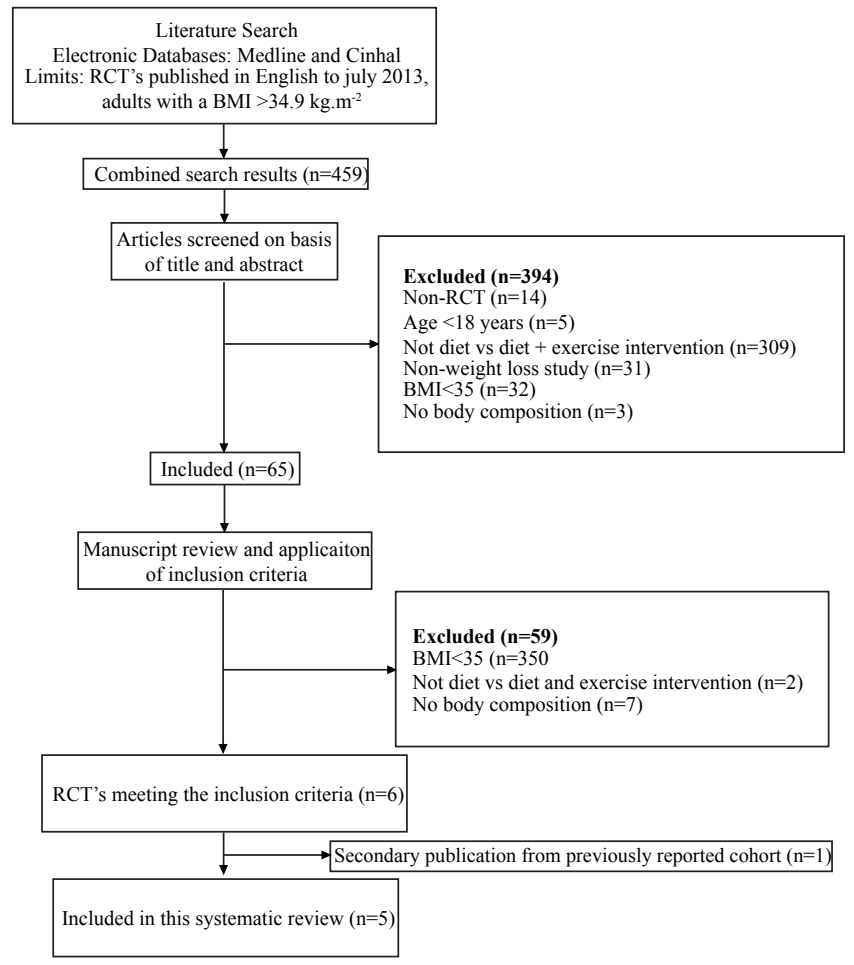

Figure 1: Method for selecting studies to include in this review. dual x-ray absorptiometry, (b) computed tomography, (c) magnetic resonance imaging, (d) under water weighing, or (e) air-displacement plethysmography (vi) a minimum of two groups (a) diet only and (b) diet combined with exercise. Outcome measures for inclusion were fat free mass and fat mass. In the case of more than one publication arising from the same study or patient cohort, the largest study only was included. Unblinded appraisal of risk of publication bias of reports to be included in the review was performed independently by $\mathrm{CM}$ and confirmed by and IL. Publications were assessed against pre-defined quality features [28] to be included in the review. These included: the method of treatment assignment; control of selection bias after treatment assignment; blinding; and outcome assessment (if blinding was not possible). Pre-specified analyses for assessing risk of bias across studies were not completed due to a lack of identified publications.

There are numerous methods used to assess body composition, all with varying degrees of reliability and validity. We chose to select only those studies that employed the use of DXA, full body MRI, airdisplacement plethysmography, and underwater weighing. These methods are most suitable for those with severe obesity despite some employing simple two compartment models that rely on algorithmic assumptions of fat free mass hydration and density which may be less accurate in this population following substantial changes in weight $[23,29]$. Methods such as bioelectrical impedance, near-infrared, total body potassium, total body water and skin folds were not included due to poor reliability during weight loss in severely obese individuals $[14,23,30,31]$

\section{Results}

\section{Studies characteristics}

A total of 459 studies from Medline and Cinahl were identified. From these, six RCTs fulfilled the inclusion criteria with one later being excluded [32] as it was a subsequent publication from the same study [33] (Figure 1). The key reason for exclusion from this review was studies employing weight loss interventions other than diet versus diet with exercise. 311 studies were excluded due to the intervention using nutritional supplements, pharmacotherapy, or differences in diet composition. An additional 82 studies were excluded due to a mean BMI below 35 in one or more of the comparison groups. A small number of studies $(n=10)$ were excluded due to body composition either not performed or bioelectrical impedance, skinfold thickness, or total body water being used to estimate body composition.

There was heterogeneity across studies in relation to the characteristics of participants. The majority of participants across the five studies were women (76\%) with a mean age ranging from 40 to 70 years. The length of intervention ranged from four to 12 months and the mean BMI of participants across the four studies ranged from 34.8 to $44 \mathrm{~kg} \cdot \mathrm{m}^{2}$. Participant adherence to the diet guidelines and attendance to consultations were recorded in two studies only $[33,34]$. Good paster and colleagues [33] reported a mean adherence of $75.1 \%$, while Wadden and colleagues [34] reported an initial attendance to diet and behavioural group sessions as $97.2 \%( \pm 7.5)$ before significantly $(\mathrm{p}<0.001)$ declining to $86.2 \%( \pm 14.4)$ for weeks 9-24. Attendance fell again in weeks $25-48$ to $65.6 \%( \pm 22.2)$, a significant reduction from the previous 15 week period. Adherence to the exercise protocols were recorded in four [34-37] studies and ranged from $56.9 \%$ to $100 \%$. One study [34] documented a reduction to exercise adherence with time. Adherence ranged from $84.3 \%( \pm 15.2), 91.5 \%( \pm 7.4)$, and $92.0 \%( \pm$ 7.9) in the first 8 weeks of the program in the aerobic, strength and combined exercise groups respectively down to $56.9 \%( \pm 24.4)$ in the 
Citation: Miller CT, Fraser SF, Straznicky NE, Dixon JB, Selig SE, et al. (2013) Effect of Diet versus Diet and Exercise on Weight Loss and Body Composition in Class II and III Obesity: A Systematic Review. J Diabetes Metab 4: 281. doi:10.4172/2155-6156.1000281

Page 3 of 6

last 15 weeks across all groups. One study [33] used an unsupervised exercise protocol of walking and tracked exercise participation objectively using a physical activity monitor. Participants were instructed to walk in excess of 10,000 steps per day. The mean steps each day in the diet plus exercise group increased from 7,048 $( \pm 2.886)$ to $8,475( \pm 2.927)$ at 6 months and doubled the amount of vigorous exercise to 71 minutes per week.

Three studies implemented a combined aerobic and resistance training program for the diet and exercise group [34-36], two studies used resistance training only [34,37], and two studies used an aerobic training protocol [33,34] (Table 1). Three studies [35-37] measured body composition using dual x-ray absorptiometry (DEXA), one study [34] used under water weighing, and the remaining study used DEXA or air-displacement plethysmography if the participants body mass exceeded 136kg [33] weight of the participants.

Exercise training duration across the studies ranged from 120 to $300 \mathrm{~min} . \mathrm{wk}^{-1}$, and was distributed over three to five days. The three combined aerobic and resistance training groups completed 20-30 minutes of moderate intensity aerobic exercise (such as brisk walking) and 20-30 minutes (2-3 sets of 6-14 repetitions) for nine to eleven different upper and lower body resistance exercises on the same three days per week [34-36]. The aerobically trained groups performed 40 60 minutes of either supervised or unsupervised aerobic exercise that consisted of moderate intensity walking or exercise videos [33,34]. The resistance training groups performed 40-45 minutes of resistance training three days per week which consisted of two sets of eight to fourteen repetitions for eight to eleven different upper and lower body exercises [34,37]. Energy intake across the studies was reduced to create a 500-750 kcal.d ${ }^{-1}$ deficit $[35,36]$ or restricted energy consumption to a range between 1,200-2,100 kcal.d $\mathrm{d}^{-1}[33,34,37]$.

\section{Risk of bias within studies}

Assessment of study quality and risk of bias was completed based on generic quality features. Blinding of the outcome assessor was reported in three $[33,35,36]$ of the five studies included. Three $[33,36,37]$ studies rated $\mathrm{b}$ or above for controlling of selection bias. Four studies [33,3537] rated $b$ or higher for method of treatment allocation. There were no analyses of the risk of bias across studies due to the paucity of publications suitable for inclusion in this review.

\section{The effect of lifestyle modification on total weight loss}

All five studies showed a significant within group body mass loss for both diet only and diet and exercise groups (Table 2). Two of the five studies reported that adding aerobic exercise [33] or resistance exercise [37] to diet intervention facilitated greater body mass loss, compared to dieting alone. In contrast, the remaining exercise groups that performed aerobic training [34], resistance training [34], or combined aerobic and resistance training [34-36] reported no significant differences in body mass loss between the diet and exercise and diet alone groups.

\section{The effect of lifestyle modification on fat mass}

Fat mass loss ranged from $5.9 \mathrm{~kg}$ to $11.6 \mathrm{~kg}$ in diet only compared with $6.3 \mathrm{~kg}$ to $14 \mathrm{~kg}$ in the diet and exercise groups. Two of the five studies showed a significantly greater fat mass loss in the diet and exercise groups using either aerobic [33] or resistance [37] training, compared to diet alone. The differences in fat mass loss in these studies were $2.8 \mathrm{~kg}$ [33] and $4.3 \mathrm{~kg}$ [37] after six and four months, respectively. No significant difference in fat mass loss between diet and diet and exercise groups for the three remaining studies was observed [34-36].

\section{The effect of lifestyle modification on lean mass}

Two of the five studies reported that diet and exercise protected from lean mass loss compared to diet alone by $1.4 \mathrm{~kg}$ [36] and $1.7 \mathrm{~kg}$ [35] using combined aerobic and resistance training in older adults with a mean age of 70 years. The remaining three studies did not show a difference in lean mass loss between diet only and diet and exercise $[33,34,37]$. We used the mean values in each study to estimate the ratio of fat mass loss to lean mass loss. Fat mass loss to lean mass loss was on average $2.9: 1 \mathrm{~kg}$ (range: $1.7: 1$ to $4.1: 1 \mathrm{~kg}$ ) for the diet only groups, $5: 1 \mathrm{~kg}$ (range: $3.3: 1$ to $7.4: 1 \mathrm{~kg}$ ) for groups that used combined aerobic and resistance exercise [34,35,36], 3.5:1 kg (range: $3.4: 1$ to $3.6: 1 \mathrm{~kg}$ ) in aerobically trained groups [33,34], 4.4:1 kg (range: 4.4:1 to $4.8: 1 \mathrm{~kg}$ ) in the resistance trained groups $[34,37]$.

\section{Discussion}

The current review reported a lack of RCTs that compared the effects of diet alone versus diet and exercise on changes in body composition in those with class II and III obesity. The limited evidence suggests that exercise training accompanied by diet may either facilitate adipose

\begin{tabular}{|c|c|c|c|c|c|c|c|}
\hline Reference & $\operatorname{Sex}(n)$ & $\begin{array}{l}\text { Mean } \\
\text { Age }\end{array}$ & Mean BMI & $\begin{array}{l}\text { Study } \\
\text { period }\end{array}$ & Dietary protocol & Exercise protocol & Exercise Attendance \\
\hline Villareal et al. [36] & $\begin{array}{l}F(33) \\
M(21)\end{array}$ & 70 & 37 & $12 \mathrm{mo}$. & $\begin{array}{l}500-750{\mathrm{kcal} . \mathrm{day}^{-1} \text { deficit }^{\wedge}} \mathrm{g} \text { protein } . \mathrm{kg}^{-1} \mathrm{BW}\end{array}$ & $3 \times 90$ min $\cdot$ wk $^{-1}$ supervised RT+AT & $83 \%$ \\
\hline $\begin{array}{l}\text { Goodpaster et } \\
\text { al. [33] }\end{array}$ & $\begin{array}{l}\mathrm{F}+\mathrm{M} \\
(117)\end{array}$ & 47 & 44 & $6 \mathrm{mo}$. & $\begin{array}{l}1,200-2,100 \mathrm{kcal} \text { day }^{-1^{\star}} \\
50-55 / 20-25 / 20-30\end{array}$ & $5 \times 60$ min wk $^{-1}$ unsupervised AT & $\begin{array}{l}20 \% \text { increase in daily steps. } 37 \\
\text { min.wk }^{-1} \text { increase in vigorous } \\
\text { exercise. }\end{array}$ \\
\hline Frimel et al. [35] & $\begin{array}{l}F(18) \\
M(12)\end{array}$ & 70 & 37 & $6 \mathrm{mo}$. & $\begin{array}{l}750 \text { kcal.day }^{-1} \text { deficit }^{\wedge} \\
50 / 20 / 30\end{array}$ & $3 \times 90$ min wk $^{-1}$ supervised RT+AT & $100 \%$ \\
\hline Wadden et al. [34] & $F(120)$ & 41 & 36 & $48 w k s$ & $\begin{array}{l}900 \mathrm{kcal}^{\text {dday }}{ }^{-1} \text { intake } \\
\text { increasing to } 1,500 \mathrm{kcal}^{- \text {day }^{-1}} \\
\text { from week } 20 \text {. } \\
55-60 / 12-15 / 15-30\end{array}$ & $\begin{array}{l}\text { AT- } 3 \times 40 \text { min.wk supervised or } \\
\text { unsupervised AT. } \\
\text { RT- } 3 \times 40 \text { min.wk }{ }^{-1} \text {, (1-2 sets } \\
\text { x } 10-14 \text { reps of } 11 \text { exercises) } \\
\text { supervised RT. } \\
\text { CT- } 3 \times 40 \text { min supervised or } \\
\text { unsupervised AT + RT. }\end{array}$ & $\begin{array}{l}84-92 \% \text { (wk1-8) } 68.7 \% \text { (wk 9-24) } \\
56.9 \% \text { (wk 25-40) }\end{array}$ \\
\hline $\begin{array}{l}\text { Wycherley et al. } \\
{[37]}\end{array}$ & $\mathrm{F}+\mathrm{M}(59)$ & 51 & 36. & $4 \mathrm{mo}$. & $\begin{array}{l}1,400-1,600 \text { kcal.day }^{-1 \#} \\
43 / 33 / 22\end{array}$ & $\begin{array}{l}3 \times 45 \text { min.wk- } 1,(2 \times 8-12 \text { of } 8 \\
\text { exercises }) \text { supervised RT }\end{array}$ & $93 \%$ \\
\hline
\end{tabular}

^energy deficit calculated individually based on food diaries or indirect calorimetry to achieve specified weight loss in the set period; "energy intake calculated on initial weight for 12 month weight loss of $8-10 \%$. "energy intake calculated on initial body weight to achieve moderate rate of weight loss; macronutrient composition (carbohydrate\%/ protein\%/fat\%); RT: Resistance Training; AT: Aerobic Training; CT: Combined Aerobic and Resistance Training

Table 1: Study characteristics. 
Citation: Miller CT, Fraser SF, Straznicky NE, Dixon JB, Selig SE, et al. (2013) Effect of Diet versus Diet and Exercise on Weight Loss and Body Composition in Class II and III Obesity: A Systematic Review. J Diabetes Metab 4: 281. doi:10.4172/2155-6156.1000281

Page 4 of 6

\begin{tabular}{|c|c|c|c|c|c|c|c|}
\hline Reference & Intervention & $\begin{array}{l}\text { Body composition } \\
\text { method }\end{array}$ & $\begin{array}{l}\Delta \text { Body Mass (kg } \\
\pm \text { SD) }\end{array}$ & \begin{tabular}{|l} 
Lean Mass \\
$(\mathrm{kg} \pm \mathrm{SD})$
\end{tabular} & $\begin{array}{l}\% \text { Lean Mass } \\
\text { Loss }\end{array}$ & $\begin{array}{l}\Delta \text { Fat Mass (kg } \\
\pm \text { SD) }\end{array}$ & $\begin{array}{l}\text { Fat Mass:Lean Mass } \\
\text { loss ratio }\end{array}$ \\
\hline \multirow[t]{2}{*}{ Villareal et al. [36] } & Diet only & DXA & $-9.7(5.4) \S$ & $-3.2(2.0) \S^{\mathrm{a}}$ & 33 & $-7.1(3.9) \S$ & $2.2: 1$ \\
\hline & $\begin{array}{l}\text { Diet plus combined aerobic } \\
\text { and resistance training }\end{array}$ & & $-8.6(3.8) \S$ & $-1.8(1.7) \S^{a}$ & 21 & $-6.3(2.8) \S$ & $3.5: 1$ \\
\hline \multirow[t]{2}{*}{$\begin{array}{l}\text { Goodpaster et al. } \\
\text { [33] }\end{array}$} & Diet only & $\mathrm{DXA}^{-}$ & $-8.2(0.87) \S^{b}$ & $-2.1(\mathrm{NR})$ & 26 & $-5.9(N R) \S^{c}$ & $2.8: 1$ \\
\hline & Diet plus aerobic training & & $-10.9(0.9) \S^{b}$ & $-2.4(\mathrm{NR})$ & 22 & $-8.7(\mathrm{NR}) \S^{\mathrm{c}}$ & $3.6: 1$ \\
\hline \multirow[t]{2}{*}{ Frimel et al. [35] } & Diet only & DXA & $-10.7(4.5) \S$ & $-3.5(2.1) \S^{b}$ & 33 & $-6.8(3.7) \S$ & $1.9: 1$ \\
\hline & $\begin{array}{l}\text { Diet plus combined aerobic } \\
\text { and resistance training }\end{array}$ & & $-9.7(4.0) \S$ & $-1.8(1.5)^{b}$ & 19 & $-7.7(2.9) \S$ & 4.3:1 \\
\hline \multirow[t]{4}{*}{ Wadden et al. [34] } & Diet only & UWW & $-14.4(6.2) \S$ & $-2.8(3.0)$ & 19 & $-11.6(N R)$ & $4.1: 1$ \\
\hline & Diet plus aerobic training & & $-13.7(8.7) \S$ & $-3.1(2.7)$ & 23 & $-10.6(N R)$ & $3.4: 1$ \\
\hline & Diet plus resistance training & & $-17.2(9.4) \S$ & $-3.2(3.4)$ & 19 & $-14(N R)$ & $4.4: 1$ \\
\hline & $\begin{array}{l}\text { Diet plus combined aerobic } \\
\text { and resistance training }\end{array}$ & & $-15.2(9.1) \S$ & $-1.8(3.9)$ & 12 & $-13.4(N R)$ & $7.4: 1$ \\
\hline \multirow[t]{2}{*}{$\begin{array}{l}\text { Wycherley et al. } \\
{[37]}\end{array}$} & Diet only & DXA & $-9.0(4.8) \S^{a}$ & $-1.9(1.5)$ & 21 & $-7.1(4.0) \S^{b}$ & $3.8: 1$ \\
\hline & Diet plus resistance training & & $-13.8(6.0) \S^{a}$ & $-2.4(3.1)$ & 17 & $-11.4(3.9) \S^{b}$ & $4.8: 1$ \\
\hline
\end{tabular}

$\%$ Lean mass loss = the calculated change in lean mass as a proportion of total mass loss; DXA: Dual X-ray Absorptiometry; UWW: Under Water Weighing; M: Male; F Female; NR: Not Reported; $\sim$ Air displacement plethysmography used if weight $>136 \mathrm{~kg}$; ${ }^{a}$ between group difference $(p<0.05)$, ${ }^{b}$ between group difference $(p \leq 0.02)$, ${ }^{c}$ between group difference $(p=0.008)$, §within group difference $(p<0.05)$

Table 2: Changes in Body Composition.

tissue loss or retard the loss of lean mass depending on the mode, total weekly exercise duration, adherence to the exercise training program and mean age of participants. However the evidence is not conclusive.

All five studies reported a loss of lean mass for both diet only and diet with exercise training. Sparing of lean mass (relative and absolute) were significant and more pronounced in the two studies that combined aerobic and resistance exercise during energy restriction where a total of 270 minutes per week was prescribed in adults with a mean age of 70 years $[35,36]$. The three remaining studies showed no significant difference in lean mass loss between diet alone and diet with exercise training with 300 minutes of moderate intensity aerobic exercise per week; or 135 minutes of either resistance training, aerobic training or combined aerobic and resistance training per week [33,34,37]. The two studies to show exercise attenuated the loss of lean mass were in older adults with a mean age of 70 years in each $[35,36]$. The non-exercise groups in each of these studies had the highest proportions of lean mass to fat mass loss of all cohorts, suggesting age may be important. In older adults weight loss is associated with an increased risk of sarcopenia, and limitation in function and mobility $[38,39]$. If weight loss is to be advised in older adults it is important that it is accompanied by an exercise program comprising both aerobic and resistance activities $[35,36]$.

Energy restriction combined with either aerobic or resistance training alone facilitated greater fat mass loss compared to their respective diet alone groups in middle aged adults [33,37]. There were no significant differences in fat mass loss between groups in the older adults $[35,36]$ or the remaining study of middle aged adults [34].

The exercise prescription across studies varied in the type, time, frequency, and intensity or volume. One study objectively measured daily physical activity [33] while others reported on exercise adherence to supervised sessions [34-37]. The average attendance across studies ranged from 56.9 to $100 \%$. Goodpaster and colleagues [33] was the only study to use an unsupervised aerobic training protocol consisting of five 60 minute moderate intensity walks per week that resulted in a significant yet small average increase in steps per day from 7048 to 8475 for their diet and exercise group and an increase in vigorous activity ( $>6$ metabolic equivalents) from 34 minutes to 88 minutes per week. The increase in the total number of steps per day corresponds to around 14 minutes of moderate intensity exercise above baseline (assuming 100 steps equates to 1 minute of walking at 3.5 MET's [40]) while there was no change in activity for the diet only group at six months. The study appears to report a much lower increase in total weekly exercise time compared with the other studies included in this review, however it is difficult to compare between these groups due to difference in assessing exercise adherence. Of those studies that reported on attendance to supervised exercise sessions [34-37], the study with the lowest adherence to the exercise training [34] was also the only study to not demonstrate either facilitation of fat mass loss or retention of lean mass in the diet and exercise group over the respective diet only group. All other studies showed that exercise in addition to diet promoted greater fat mass loss $[33,37]$ or retained more lean mass $[35,36]$ than their corresponding diet only groups. Those studies reporting the most promising body composition results [35-37] reached $83-100 \%$ exercise compliance, being two to three times the exercise duration per week than the study with the lowest exercise adherence [34] (125-224 min. $\mathrm{wk}^{-1}$ compared with $\left.68 \mathrm{~min} . \mathrm{wk}^{-1}\right)$. This may highlight the importance of increasing adherence to exercise in this clinical population. It is possible that in class II and III obesity the participation rate in physical activity and adherence to exercise training, is more important for improving body composition (i.e. reduce fat mass and increase lean tissue) than the specific activity perse. In other words, as long as those individuals are involved in some form of exercise, aerobic, resistance or a combination, they increase their chance to get positive body composition changes.

A limitation of the current review is the small number of studies that met the inclusion criteria. We have used tight inclusion criteria based on study design (RCTs), exercise interventions (mode and duration) and methods to assess fat mass and fat free mass. The small number of studies available is in disproportion to the number of people 
Citation: Miller CT, Fraser SF, Straznicky NE, Dixon JB, Selig SE, et al. (2013) Effect of Diet versus Diet and Exercise on Weight Loss and Body Composition in Class II and III Obesity: A Systematic Review. J Diabetes Metab 4: 281. doi:10.4172/2155-6156.1000281

with $\mathrm{BMI} \geq 35 \mathrm{~kg} \cdot \mathrm{m}^{2}$ who may benefit from exercise training, and so more studies are needed.

\section{Conclusion}

Adherence to exercise training during energy restriction for individuals with $\mathrm{BMI} \geq 35 \mathrm{~kg} \cdot \mathrm{m}^{2}$ may either facilitate fat mass loss or preserve fat free mass compared to diet alone, but the evidence is limited. Further studies should focus on the efficacy of different exercise training protocols when added to dietary interventions for people with $\mathrm{BMI} \geq 35 \mathrm{~kg} \cdot \mathrm{m}^{2}$, both in terms of weight loss and changes to body composition in order to better inform decision making for the prescription of exercise for severely obese individuals.

\section{Acknowledgements}

Dr. Itamar Levinger is a Heart Foundation Postdoctoral Research Fellow (PR $11 \mathrm{M}$ 6086). Prof John Dixon is an NHMRC Senior Research Fellow.

\section{References}

1. AlHW (2010) Australia's health 2010. In: Welfare AloHa, editor. (12thedn), Canberra: AlHW

2. Sturm R (2007) Increases in morbid obesity in the USA: 2000-2005. Public Health 121: 492-496.

3. Dixon JB (2010) The effect of obesity on health outcomes. Mol Cell Endocrinol 316: 104-108.

4. Walls HL, Wolfe R, Haby MM, Magliano DJ, de Courten M, et al. (2010) Trends in BMI of urban Australian adults, 1980-2000. Public Health Nutr 13: 631-638.

5. Andreyeva T, Sturm R, Ringel JS (2004) Moderate and severe obesity have large differences in health care costs. Obes Res 12: 1936-1943.

6. McLennan J (2004) Obesity in children. Tackling a growing problem. Aust Fam Physician 33: 33-36.

7. Jakicic JM, Clark K, Coleman E, Donnelly JE, Foreyt J, et al. (2001) American College of Sports Medicine position stand. Appropriate intervention strategies for weight loss and prevention of weight regain for adults. Med Sci Sports Exerc 33: $2145-2156$

8. NHMRC (2013) Clinical practice guidelines for the management of overweigh and obesity in adults, adolescents and children in Australia - Systematic Review. In: Council NHMR, editor. Canberra: Commonwealth of Australia.

9. Després JP, Lemieux I (2006) Abdominal obesity and metabolic syndrome Nature 444: 881-887.

10. Thörne A, Lönnqvist F, Apelman J, Hellers G, Arner P (2002) A pilot study of long-term effects of a novel obesity treatment: omentectomy in connection with adjustable gastric banding. Int J Obes Relat Metab Disord 26: 193-199.

11. Chaston TB, Dixon JB (2008) Factors associated with percent change in visceral versus subcutaneous abdominal fat during weight loss: findings from a systematic review. Int J Obes (Lond) 32: 619-628.

12. Ross R, Dagnone D, Jones PJ, Smith H, Paddags A, et al. (2000) Reduction in obesity and related comorbid conditions after diet-induced weight loss or exercise-induced weight loss in men. A randomized, controlled trial. Ann Intern Med 133: 92-103.

13. Chaston TB, Dixon JB, O'Brien PE (2007) Changes in fat-free mass during significant weight loss: a systematic review. Int J Obes (Lond) 31: 743-750.

14. Marks BL, Rippe JM (1996) The importance of fat free mass maintenance in weight loss programmes. Sports Med 22: 273-281.

15. Miller GD, Nicklas BJ, Loeser RF (2008) Inflammatory biomarkers and physical function in older, obese adults with knee pain and self-reported osteoarthritis after intensive weight-loss therapy. J Am Geriatr Soc 56: 644-651.

16. Weiss EP, Racette SB, Villareal DT, Fontana L, Steger-May K, et al. (2007) Lower extremity muscle size and strength and aerobic capacity decrease with caloric restriction but not with exercise-induced weight loss. J Appl Physiol 102 $634-640$

17. Weinheimer EM, Sands LP, Campbell WW (2010) A systematic review of the separate and combined effects of energy restriction and exercise on fat-free mass in middle-aged and older adults: implications for sarcopenic obesity. Nutr Rev 68: 375-388.
18. Strasser B, Schobersberger W (2011) Evidence for resistance training as a treatment therapy in obesity. J Obes 2011

19. Dickinson HO, Mason JM, Nicolson DJ, Campbell F, Beyer FR, et al. (2006) Lifestyle interventions to reduce raised blood pressure: a systematic review of randomized controlled trials. J Hypertens 24: 215-233.

20. Avenell A, Brown TJ, McGee MA, Campbell MK, Grant AM, et al. (2004) What interventions should we add to weight reducing diets in adults with obesity? A systematic review of randomized controlled trials of adding drug therapy, exercise, behaviour therapy or combinations of these interventions. J Hum Nutr Diet 17: 293-316.

21. Garrow JS, Summerbell CD (1995) Meta-analysis: effect of exercise, with or without dieting, on the body composition of overweight subjects. Eur $\mathrm{J}$ Clin Nutr 49: 1-10.

22. Going SB, Massett MP, Hall MC, Bare LA, Root PA, et al. (1993) Detection of small changes in body composition by dual-energy $\mathrm{x}$-ray absorptiometry. Am J Clin Nutr 57: 845-850.

23. Woodrow $G$ (2007) Body composition analysis techniques in adult and pediatric patients: how reliable are they? How useful are they clinically? Peritoneal dialysis international : journal of the International Society for Peritoneal Dialysis 27: S245-249.

24. Lau DC, Douketis JD, Morrison KM, Hramiak IM, Sharma AM, et al. (2007) 2006 Canadian clinical practice guidelines on the management and prevention of obesity in adults and children [summary]. CMAJ 176: S1-13.

25. NHMRC (2003) Clinical practice guidelines for the management of overweight and obesity in adults. In: Council NHMR, editor. Canberra: Commonwealth of Australia.

26. Tsigos C, Hainer V, Basdevant A, Finer N, Fried M, et al. (2008) Management of obesity in adults: European clinical practice guidelines. Obes Facts 1: 106116 .

27. (1998) Clinical Guidelines on the Identification, Evaluation, and Treatment of Overweight and Obesity in Adults--The Evidence Report. National Institutes of Health. Obes Res 6 Suppl 2: 51S-209S.

28. Glasziou P (2001) Systematic reviews in health care: a practical guide. New York: Cambridge University Press.

29. Fields DA, Higgins PB, Radley D (2005) Air-displacement plethysmography: here to stay. Curr Opin Clin Nutr Metab Care 8: 624-629.

30. Alvarez VP, Dixon JB, Strauss BJ, Laurie CP, Chaston TB, et al. (2007) Single frequency bioelectrical impedance is a poor method for determining fat mass in moderately obese women. Obes Surg 17: 211-221.

31. Das SK (2005) Body composition measurement in severe obesity. Curr Opin Clin Nutr Metab Care 8: 602-606

32. Cooper JN, Columbus ML, Shields KJ, Asubonteng J, Meyer ML, et al. (2012) Effects of an intensive behavioral weight loss intervention consisting of caloric restriction with or without physical activity on common carotid artery remodeling in severely obese adults. Metabolism 61: 1589-1597.

33. Goodpaster BH, Delany JP, Otto AD, Kuller L, Vockley J, et al. (2010) Effects of diet and physical activity interventions on weight loss and cardiometabolic risk factors in severely obese adults: a randomized trial. JAMA 304: 1795-1802.

34. Wadden TA, Vogt RA, Andersen RE, Bartlett SJ, Foster GD, et al. (1997) Exercise in the treatment of obesity: effects of four interventions on body composition, resting energy expenditure, appetite, and mood. J Consult Clin Psychol 65: 269-277.

35. Frimel TN, Sinacore DR, Villareal DT (2008) Exercise attenuates the weightloss-induced reduction in muscle mass in frail obese older adults. Med Sci Sports Exerc 40: 1213-1219.

36. Villareal DT, Chode S, Parimi N, Sinacore DR, Hilton T, et al. (2011) Weigh loss, exercise, or both and physical function in obese older adults. $\mathrm{N}$ Engl $\mathrm{J}$ Med 364: 1218-1229.

37. Wycherley TP, Noakes M, Clifton PM, Cleanthous X, Keogh JB, et al. (2010) A high-protein diet with resistance exercise training improves weight loss and body composition in overweight and obese patients with type 2 diabetes. Diabetes Care 33: 969-976

38. Bannerman E, Miller MD, Daniels LA, Cobiac L, Giles LC, et al. (2002) Anthropometric indices predict physical function and mobility in olde Australians: the Australian Longitudinal Study of Ageing. Public Health Nutr 5: 655-662. 
Citation: Miller CT, Fraser SF, Straznicky NE, Dixon JB, Selig SE, et al. (2013) Effect of Diet versus Diet and Exercise on Weight Loss and Body Composition in Class II and III Obesity: A Systematic Review. J Diabetes Metab 4: 281. doi:10.4172/2155-6156.1000281

Page 6 of 6

39. Miller SL, Wolfe RR (2008) The danger of weight loss in the elderly. J Nutr Health Aging 12: 487-491.
40. Ohkawara K, Tanaka S, Miyachi M, Ishikawa-Takata K, Tabata I (2007) A dose-response relation between aerobic exercise and visceral fat reduction: systematic review of clinical trials. Int J Obes (Lond) 31: 1786-1797.

This article was originally published in a special issue, Type 2 Diabetes Mellitus- Disease, Diagnosis \& Treatment handled by Editors. Dr. Judit Bene, University of Pécs, Hungary; Eun Seok Kang, Yonsei University College of Medicine, Korea 